\title{
An Investigation of IT Users' Emotional Responses to Technostress Creators
}

\author{
Jalal Sarabadani \\ Washington State University \\ jalal.sarabadani@wsu.edu
}

\author{
Deborah Compeau \\ Washington State University \\ deborah.compeau@wsu.edu
}

\author{
Michelle Carter \\ University of Alabama \\ mscarter3@cba.ua.edu
}

\begin{abstract}
While prior research on technostress has examined its different adverse effects, the role of emotion has largely been ignored. Emotions play a major role in individuals' beliefs and guide their behavior and decision-making process. Thus, it is essential to understand how IT users emotionally respond under the presence of technostress creators in the workplace. To that end, this paper seeks to identify different emotional responses induced by technostress creators. We surveyed 188 employees from different industries and used path modelling techniques to analyze the data. The results of the research show that techno-overload and techno-complexity are significant predictors of negative emotions. Moreover, while techno-complexity is negatively associated with positive emotions, techno- uncertainty was positively associated with positive emotions. The influences of other technostress creators, such as techno-invasion and techno-insecurity are less clear. More research is needed to identify outcomes of emotions associated with each technostress creator and to provide a foundation for effective managerial interventions.
\end{abstract}

\section{Introduction}

John is an administrative assistant at a relatively big company. While working on a report, he usually accesses multiple IT resources, including email, an internal shared folder, Dropbox, and Slack - a collaboration software. John feels that the number of IT resources required to complete the report hinders him from accomplishing his task effectively. He is frustrated and angry.

Alex works for a tech company which has recently implemented an ERP system. The system is quite complex and there are so many technical terms associated with it that Alex needs to learn. Alex feels overwhelmed by the task ahead and is becoming worried and stressed out.
As these opening vignettes show, use of IT can impact individuals in different ways. One common way is that it increases the expectation from managers that employees work faster and get more things done. While use of IT facilitates doing tasks, it puts a lot of pressure on employees leading to a specific type of stress called technostress. The term technostress was defined as the inability of individuals to use technology in a healthy manner [6]. In our vignettes, John has a feeling of anger while Alex is worried because of the technologies they use at work. Technostress has been conceptualized as a secondorder construct comprising five first-order constructs that reflect technostress creators: techno-overload, techno-invasion, techno-complexity, technoinsecurity and techno-uncertainty $[28,21]$. While the literature on technostress has mainly focused on its negative psychological and behavioral outcomes [30, 4, 19], recent work has begun to investigate mechanisms through which technostress leads to such outcomes [10, 20, 32].

As the literature shifts its focus to the different coping mechanisms that individuals use to deal with technostress, it has largely ignored the role of emotions. Literature from psychology shows that emotions are tightly associated with stress [17]. Emotions strongly influence humans' beliefs, behaviors, and guide their thinking and decision making process [5]. Furthermore, "stress tells us little about the details of a person's struggle to adapt while emotions include a variety of categories, greatly increasing the richness of understanding of what can be said about a person's adaptational struggle" [17]. Hence, it is important to investigate how technostress is linked with peoples' emotions. This leads to the following research question: What are the different emotions induced from technostress creators?

This paper makes several contributions. First, extant research has examined the adverse effects of technostress creators and individuals' coping mechanisms but little attention has been paid to how they emotionally respond to these stressors. Our research draws on the technostress literature and 
Beaudry and Pinsonneault's framework of emotions [5] to explain how people emotionally react to each technostress creator. Second, most prior research has looked at technostress as a second-order construct. Since technostress creators are different from one another, however, it is reasonable to assume that people may respond to them differently. To explore this possibility, this research focuses on technostress creators separately, to provide a more granular level of analysis and theoretical reasoning with regard to the emotional responses associated with each.

The rest of the paper is organized as follows. In the following section, we present the literature review on technostress and emotions. Next, we develop the research model and hypotheses. Then, we present our research method, along with our findings and discussion. Finally, we conclude by highlighting the research and practical contributions of the paper, its limitations and future directions.

\section{Literature review}

\subsection{Technostress literature}

Drawing upon the stress literature in psychology, technostress has been conceptualized as a secondorder construct, comprised of five stress creating factors known as techno-overload, techno-invasion, techno-complexity, techno-insecurity and technouncertainty [28]. Most of the research on technostress has focused on the relationship between it and its associated strains. Major studies in this area have investigated the negative impacts of technostress on employees' satisfaction, performance, productivity and commitment [31, 21, 29, 13, 27 3, 14, 24]. Additionally, technostress creators and their impacts have been examined in different contexts such as social networks, email, smartphones and general use of IT $[29,19,23,26]$.

A recent stream of technostress research has shifted the focus to explain the role of individuals' coping strategies in mediating the negative effects of technostress creators. One of the early studies contextualized technostress in the context of information security and explained how individuals use neutralization as a coping mechanism to violate information security policies in organizations [8]. Another looked at the role of distancing, venting and IT control in moderating the relationship between technostress and strain [20]. Their results showed that distancing and venting reduce the impacts of technostress on strain when IT control is low. Furthermore, Gaudioso and colleagues [10] used adaptive and maladaptive coping strategies to explain the impact of two specific technostress creators namely techno-invasion and techno-overload on workplace outcomes such as work exhaustion. Their findings showed that adaptive coping strategies decrease work exhaustion while maladaptive ones have the opposite effect. Moreover, results from recent research show that people use proactive coping to deal with technostress and reactive coping to deal with emotional exhaustion [32].

\subsection{Transactional model of stress and framework of emotions}

Stress is tightly coupled with emotions [17]. It is argued that whenever there is stress, "stress emotions" [17] are there as well. Emotions are "mental state of readiness for action that promote behavioral activation" $[5,2]$. Emotions arise in response to the appraisal of an event perceived to be important to an individual [5]. A deeper understanding about emotions associated with stress can help explain how individuals evaluate their transactions with the environment and how they react to it.

The relationship between stress and emotion has been well-established in the psychology literature $[18,17]$. Emotions have been argued to be coupled with stress because the stressors impact people's emotion which in turn influence their behavior. The Transactional Model of Stress (TMS) [18] is the underlying theoretical foundation that has been used to delineate the importance of emotions as a response to stressors. According to TMS, people evaluate a stressful situation by going through two phases of appraisal. In the primary appraisal phase, they evaluate whether the stressful situation is threatening or challenging. In the secondary appraisal phase, they assess their level of control over the situation. Depending on their evaluations from primary and secondary appraisal, people experience different emotional responses. These responses can range from positive emotions, such as enthusiasm and happiness, to negative emotions, such as anxiety and frustration.

The IS literature has also investigated the importance of emotions in relation to technological events. Beaudry and Pinsonneault relied on the appraisal theories of emotions from psychology literature $[18,16]$ to develop a framework of emotions and test how awareness of an IT event impacts their subsequent IT use through emotions. Their framework classifies emotions into four groups: achievement emotions, challenge emotions, loss emotions and deterrence emotions.

Achievement emotions appear when a user evaluates an IT event as an opportunity over which s/he has control. Achievement emotions include 
happiness, satisfaction, pleasure, relief and enjoyment. Challenge emotions emerge when a situation is evaluated as an opportunity but the user has limited to no control over it. Challenge emotions include

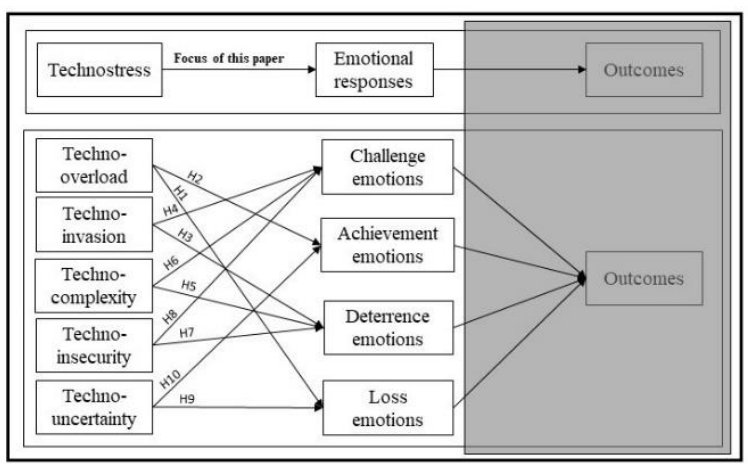

Figure 1. Research Model

excitement, hope, anticipation, arousal, playfulness and flow. Loss emotions occur when users evaluate an IT event as a threat over which they have some extent of control. Loss emotions include anger, frustration, disgust, dissatisfaction, disappointment and annoyed. Finally, deterrence emotions arise from perceiving an IT event as a threat over which one has limited or no control. Deterrence emotions include anxiety, fear, worry and distress. This study uses this framework of emotions as its theoretical underpinning to understand different emotional responses individuals have to technostress creators.

\subsection{Related work on emotion and technostress.}

Very few studies have investigated the emotional responses of IT users to technostress creators and to the best of our knowledge this is among the first research endeavors to explore the role of emotions in this context. In one recent study, Weinert and colleagues [20] examined the moderating role of emotional coping responses on the relationship between stressors and strain. Their results showed that distress venting, which is expressing your feelings from IT decreased work exhaustion under the presence of IT control. Still, prior research has looked at emotion from a broad perspective and has not taken a granular analysis of specific emotions. Identifying the range of emotions induced from each of the technostress creators will enrich our understanding of the subsequent individuals' behavior. This helps researchers and practitioners to provide specific interventions to alleviate the negative impacts of each technostress creator. The rest of the paper draws upon the emotion framework introduced earlier to examine the role of emotions in the relationship between technostress and strains associated with it.

\section{Research model and hypotheses development}

The research model in this paper (Figure 1) takes its theoretical view from the Transactional Model of Stress (TMS) and framework of emotions to investigate the relationship between technostress creators and emotions associated with them. The upper half of Figure 1 shows the general relationship between stressors, emotion and strain while the bottom half of the model shows the specific stressors and emotional responses examined in this study. In the remainder of this section, we explain each of our proposed hypotheses.

Advances in technology have made it possible to access information from a variety of sources [1, 37]. Techno-overload is associated with handling different streams of information simultaneously which increases the expectation from individuals to work faster and harder [21]. Information overload has been shown to have adverse effects on people's ability to make timely decisions [25]. Moreover, this excessive load of information hinders employees' accomplishment of their other work-related tasks [21]. Based on TMS, we argue that people with technooverload perceive such technologies as a threat over which they have limited control due to policies of organizations to store data or internal and external sources of information to communicate (such as email) or collaborate (such as Dropbox) with others. These multiple sources of information are likely to lead to negative emotions if they are not helpful to individuals in decision making process. Such negative emotions fall into the category of loss emotions as techno-overload is perceived to be a threat over which employees have limited to no control. This view is supported by literature showing that information overload is negatively associated with job satisfaction and positively related to anger and frustration [9]. Similarly, drawing upon TMS and the framework of emotions, we argue that individuals with higher levels of techno-overload are less likely to show enjoyment because they have to work with multiple internal and external sources of information simultaneously. Moreover, since they have to frequently refer to these sources, this negatively impacts their general satisfaction of their job resulting in being less pleased. Therefore, we hypothesize that:

H1. Techno-overload is positively associated with loss emotions. 
H2. Techno-overload is negatively associated with achievement emotions.

Techno-invasion describes a situation where employees are expected to be constantly available anytime and anywhere [21]. Such situations extend their working hours and individuals often feel they have to be responsive of work-related tasks. More importantly, techno-invasion affects the quality time individuals should spend with their family and friends which can lead to personal tensions [4]. Therefore, according to TMS, techno-invasion is perceived to be a threat over which individuals have some extent of control since they have the ability to choose the amount of their family time they sacrifice for work purposes by frequently checking available technologies to them. Thus, the idea of working at home for work-related tasks during family time can blur personal relationships and give rise to deterrence emotions, such as guilt and distress [15, 4]. Moreover, they are likely to worry about their relationships with people around them. The tension that people experience in their personal lives due to technoinvasion, leads to fewer challenge emotions, such as being less hopeful and energized. Thus, we propose the following hypotheses:

H3: Techno-invasion is positively associated with deterrence emotions.

H4: Techno-invasion is negatively associated with challenge emotions.

Techno-complexity occurs when technology is perceived to be complex as a result of which individuals need to expend considerable amount of time learning new terms and reading manuals associated with it [21]. In such cases, employees may find themselves to be less knowledgeable compared to their peers and feel the need to improve their knowledge and learn more [28, 8]. Based on TMS, they may seek out available resources, such as training, searching online or reading manuals, to deal with techno-complexity. However, continuous learning with regard to the complexity of a technology can result in deterrence emotions. For example, Yaverbaum [33] showed that individuals experience a sense of fear and anxiety when they perceive a technology to be complex. Furthermore, in another study, it was shown that complexity of a technology is a strong predictor of anxiety in people, especially in older individuals [11]. Similarly, we argue that users who perceive techno-complexity as a threat to their work are less excited about utilizing IT in their daily work and do not feel energized when using complex technologies. Thus, we hypothesize that:

H5: Techno-complexity is positively associated with deterrence emotions.
H6: Techno-complexity is negatively associated with challenge emotions.

Techno-insecurity is associated with the feeling that automated systems or more knowledgeable employees will replace an individual [21]. In such cases, individuals feel threatened by other colleagues who are more knowledgeable and they are likely to even avoid sharing their knowledge with others. According to TMS, while individuals may perceive technology as threatening they have some extent of control over it. For instance, they may be able to take some action to keep up with the technology, such as boosting their knowledge [30]. Nevertheless, individuals experiencing techno-insecurity are likely to express feelings of anxiety and distress. They may have little hope about their job and feel less excited to learn the technology for the purpose of improving their knowledge. Therefore, we propose that:

H7: Techno-insecurity is positively associated with deterrence emotions.

H8: Techno-insecurity is negatively associated with challenge emotions.

Techno-uncertainty occurs when individuals are not given enough time to have solid experience with technology at work. Commonly, organizations utilize or develop new technologies, such as making continuous changes or amendments in their enterprise systems, to improve their work processes. For example, an organization may implement new security systems and require employees to frequently adapt to security policies. Such changes can be evaluated as a threat because they increase individuals' workload and extend their working hours in addition to forcing them to spend time learning about new technologies and policies. Loss emotions are likely responses in such situations. Since users have limited to no control over such changes, they are likely to show feelings of dissatisfaction, frustration and even anger. An evident example of this is the work of Beaudry and Pinsonneault [5], which investigated how the introduction of a new system created feelings of anger and led to less use of that IT. Additionally, individuals experiencing techno-uncertainty are less satisfied and pleased with their job due to such frequent changes in their organizations Therefore, we propose the following hypotheses:

H9: Techno-uncertainty is positively associated with loss emotions.

H10: Techno-uncertainty is negatively associated with achievement emotions.

\section{Research methodology: design and measurement}


To test our research model, we collected data from 188 individuals. The study population includes employees of organizations who use technology frequently in their job and work as a full-time employee. To sample from this population, we used a national survey panel from Qualtrics ${ }^{\mathrm{TM}}$, an aggregator of market research panels.

We chose Qualtrics for several reasons. First, online market panels make it possible to capture data from a diverse population of respondents [38]. Second, online research panels provide access to a large population of respondents. Third, filtering options make it possible to screen out respondents who do not match the sampling frame [39]. Finally, online panels provide built-in anonymity and features to ensure data quality [40].

Qualtrics ${ }^{\mathrm{TM}}$ sent the survey to a random selection of panel members residing in the United States of America who were over the age of 18 and full-time employees. We used well-established with appropriate modifications to fit them into our context. We measured technostress creators using scales from the papers which developed these constructs $[28,21]$. We also used the framework of emotions from Beaudry and Pinsonneault [5] and adapted them.

In total, we received 220 complete responses. To ensure the quality of our data, we followed the procedures suggested by Burleson et al. [9] for data screening, ending up with 188 valid responses. Males comprised $35 \%$ of the sample, while females comprised $64.10 \%$, with $2 \%$ stating their gender as other. The age groups were categorized as follows: under 30 years $(19.4 \%), 31-40 \quad(30.1 \%), 41-50$ $(26.2 \%)$, above 50 years $(24.3 \%)$. The results of level of education showed that around $10 \%$ of the respondents had high school education, $22.3 \%$ had some college but no degree, $11.2 \%$ had an associate's degree, $34.5 \%$ had bachelor's degree, $15 \%$ finished master's degree, and $6.1 \%$ had doctorate and professional degree. We also measured the number of years our respondents had used IT in the workplace. Respondents who utilized IT for less than 5 years accounted for $27.7 \%, 9.7 \%$ had experience of using IT at work between 5 to 10 years, $19.4 \%$ had been using IT between 11 to 15 years, and $28.2 \%$ had been working with IT at work for more than 15 years. Data were captured from people with IT experience in a diverse set of job categories, including: management and business (19.7\%); computer, engineering and science (13.8\%); education, legal, community and media (14.4\%); health care $(12.2 \%)$; sales $(9.0 \%)$; service $(7.4 \%)$ and office and administrative occupations $(6.9 \%)$. Full demographic information is provided in Table 1 of the Appendix.

\section{Data analysis and results}

\subsection{Reliability and validity}

We tested our research model using path modeling techniques, implemented in SmartPLS 3.2.6 [22]. In IS, path modeling techniques have been recommended when the objective is to test path-specific hypotheses rather than to confirm a theory-based structural model [35]. As such, PLS was deemed an appropriate technique for understanding the relationships between techno-stressors and emotions. All of our first-order constructs were reflective. Each of the reflective constructs exhibited high reliability and average variance extracted. The individual item loadings were all above 0.70 except in 3 cases. One of the measures of techno-complexity had a loading of 0.57 , one item of techno-insecurity had a loading of 0.62 and an indicator of challenge emotion had a loading of 0.57 . We removed the first two items because of low loadings. We kept the challenge emotion item to have minimum 3 number of items for the construct. The Average Variance Extracted (AVE) which has been recommended to be over 0.5 also supported the validity of the constructs. Cross loadings were all lower than the loadings, and the FornellLarcker test of discriminant validity (Table 3 in the Appendix) showed that some of the constructs were highly correlated. Challenge and achievement emotions are an example. The reason might be they are all positive emotions [12]. For further analysis we checked Heterotrait-Monotrait (HTMT) Ratio values. All values for the Heterotrait-Monotrait (HTMT) Ratio were lower than the 0.9 recommended cutoff [34]. Thus, reliability and discriminant validity were satisfied. Questionnaire items and their loadings are listed in table 2 of the Appendix.

\subsection{Test of the model}

Figure 2 shows the results of the structural model. The results show that techno-overload increases the likelihood of loss emotions $(b=0.27, p<.01)$ which supports our first hypothesis. However, the influence of techno-overload on achievement emotions is not significant $(b=-0.14, p=.10)$. With regard to our third and fourth hypotheses, techno-invasion has no influence on either deterrence $(b=0.12, p=.22)$ or challenge emotions $(b=0.10, p=.54)$. Technocomplexity is a significant predictor of deterrence emotions $(b=0.48, p<.001)$ supporting hypothesis five. In a similar vein, techno-complexity strongly influences challenge emotions $(b=-0.36, p<.001)$ providing support for hypothesis six. With regard to 
techno-insecurity, the results show that the influence of techno-insecurity on deterrence emotions is nonsignificant $(b=0.00, p=.99)$ which does not support hypothesis seven. Similarly, techno-insecurity does not influence challenge emotions significantly $(b=$ $0.24, \mathrm{p}=.054$ ) which does not support hypothesis eight. Like techno-invasion, techno-uncertainty does not significantly influence loss emotions $(b=-0.05, p=$ .64) while it significantly influences achievement emotions $(b=0.32, p<.05)$ showing the relationship is significant but at the opposite direction.

Overall, the model explains $10 \%$ of variance for achievement emotions, $9 \%$ of variance for challenge emotions, $30 \%$ of variance in deterrence emotions and $6 \%$ of variance in loss emotions. The figure below shows the structural model results.

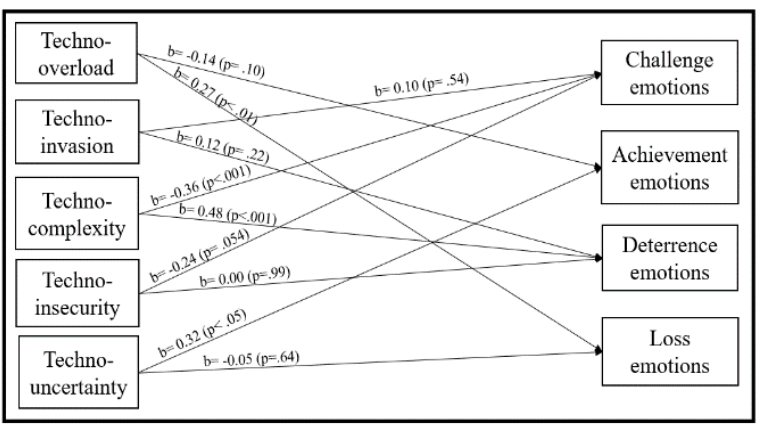

Figure 2. PLS Structural Model Results

\section{Discussion}

This study aimed to shed light on the relationships between technostress creators and different types of emotions. Our results showed that techno-complexity is a strong predictor of deterrence emotions and challenge emotions. This is in line with prior research showing that users who perceive technologies to be complex exhibit feelings, such as anxiety. We argue that employees experience deterrence emotions because they feel that technology makes their job harder and they might lose their reputation at work. They might even be underestimated by their peers or supervisors by not being able to keep up with the technology and falling behind their work-related tasks. At the extreme, this situation could even cause them lose their jobs. As a result, the complexity of the technology makes individuals less excited and energized toward the technology.

Surprisingly, the relationships between technoinsecurity and techno-invasion with deterrence and challenge emotions were non-significant. One explanation for this finding might be that employees under such types of stressors experience other forms of deterrence or challenge emotions that were not captured or conceptualized to analyze in this study. Additionally, the context of the study might have played a role in these results. Future studies may seek to validate our findings in a specific technology context. As an example to support this argument, a person with techno-invasion can be on the one hand worried about his/her personal relationship and on the other hand show anger, frustration and dissatisfaction to his/her job due to constant connectivity. Alternatively, future research could employ qualitative methods, such as interviews, to uncover feelings associated with techno-invasion and technoinsecurity.

Techno-overload was a strong predictor of loss emotions, which supports our arguments that using multiple IT resources to complete work tasks places a burden on employees, leading to frustration, anger and job dissatisfaction. These feelings can impede employees' decision-making abilities.

Surprisingly, techno-uncertainty was a significant predictor of achievement emotions. This could be explained by the fact that with ubiquitous computing, people are constantly tracking new technologies so that techno-uncertainty does not impact their emotions substantially. Furthermore, new technologies offer new features that individuals look forward to working with and that may give them positive feelings such as a sense of happiness and pleasure. These findings should be investigated to determine whether there are differences in emotional responses to corporate vs. consumer technologies.

\section{Theoretical and practical contributions}

This study contributes to the literature in the following ways. First, prior technostress literature has focused on the psychological and behavioral responses. This study explores the role of individuals' emotional responses to technostress. Second, we extend the literature by investigating the separate influences of technostress creators, rather than the influence of technostress as a second-order construct. This allowed us to better articulate the nature of each technostress creator and to examine their differential influences on emotions. In doing so, we revealed that technostress creators may stimulate different classes of emotions and may influence emotions in surprising ways.

From a practical standpoint, technostress is costly for organizations because it can lead to ineffective and inefficient use of IS by employees. Our research helps managers to identify the most salient technostress creators (in our case techno-complexity and techno- 
overload) to which employees show negative emotional responses. These understandings could serve as a basis for mangers to design appropriate intervention to reduce the negative impacts of technostress creators.

\section{Limitations and future research}

This research is not without limitations. First, our research model is unable to explain what emotions are associated with technostress creators such as technoinvasion and techno-insecurity. Future endeavors can investigate these technostress creators using different theoretical perspectives and/or different methodological approaches.

Another limitation is associated with collecting data from a wide range of professionals and IT in general. We acknowledge that collecting data from the general population about information technology in generic rather than a specific tool may limit our ability to find job- and technology-specific moderators of the relationships between technostress creators and emotions. Our choice, however, is consistent with research on technostress, which focuses on the stresses created by the use of information technologies broadly [21] such as the overload created by the "always on" mentality that comes from the way we use a whole class of information technologies such as email, cell phones, social media etc. Future research may seek to investigate the relationship between stressors at a more specific IT or use context and employees' emotional response.

Third, we looked at emotions from a variance model perspective that considered technostress creators as a threat. However, not everyone perceives these as a threat and some technostress creators might be seen as opportunities. Future work could take a process perspective and identify circumstances under which technostress creators are perceived as threats vs. opportunities. Doing so, will make it possible to examine the stability of technostress creators' influences across contexts.

Fourth, PLS components incorporate variance due to error, as well as "true" variance. Consequently, the technique may overstate components' loadings, reliabilities and average variance extracted, while deflating correlations between components [36]. As such, PLS offers approximate, rather than precise, statistical tests of hypotheses and the results presented should be considered preliminary. In future, we intend to use the findings of this work to develop a theorybased structural model that incorporates individuals' emotional responses to techno stressors, together with the outcomes of those responses. Such a model would be appropriately tested using more accurate covariance-based SEM techniques.

Fifth, in using a survey method, we captured individuals' self-reports of their emotions. Other methods for assessing emotions, such as facial expression analysis have been suggested [41], and would provide additional evidence regarding the model. Moreover, using multiple methods would help to reduce the threat of common method bias.

Finally, in this paper we did not consider the impact of emotional responses on outcomes as a result of technostress creators. Future work can also explore the subsequent impacts of emotions on individuals and the adaptation strategies that individuals use to overcome technostress.

\section{Conclusion}

The present paper investigated how users emotionally respond to technostress creators. We explored how each technostress creator impacts individuals' emotions. The results showed that technooverload and techno-complexity are the most salient stressors that lead to negative classes of emotions. In addition, this research showed that each technostress creator can lead to a different class of emotions. We conclude that understanding emotional responses of individuals to technostress is important because it drives their future behaviors, attitude and their decision making.

\section{References}

[1] Addas, S. and A. Pinsonneault (2015). "The many faces of information technology interruptions: a taxonomy and preliminary investigation of their performance effects." Information Systems Journal 25(3): 231-273.

[2] Adelaar, T., S. Chang, K. M. Lancendorfer, B. Lee and M. Morimoto (2003). "Effects of media formats on emotions and impulse buying intent." Journal of Information Technology 18(4): 247-266.

[3] Ahmad, U. N. U., S. M. Amin and W. K. W. Ismail (2014). "Moderating effect of Technostress inhibitors on the relationship between Technostress creators and organisational commitment." Jurnal Teknologi 67(1): 51-62.

[4] Ayyagari, R., V. Grover and R. Purvis (2011). "Technostress: technological antecedents and implications." MIS quarterly 35(4): 831-858.

[5] Beaudry, A. and A. Pinsonneault (2010). "The other side of acceptance: studying the direct and indirect effects of emotions on information technology use." MIS quarterly: 689-710. 
[6] Brod, C. (1984). Technostress: The human cost of the computer revolution, Addison Wesley Publishing Company.

[7] Burleson, James; Carter, Michelle; and Sarabadani, Jalal, "On the importance of data quality in information systems research and ph.d. curricula" (2019). 2018 Proceedings. 18.

[8] D'Arcy, J., T. Herath and M. K. Shoss (2014). "Understanding employee responses to stressful information security requirements: A coping perspective." Journal of Management Information Systems 31(2): 285-318.

[9] Edmunds, A. and A. Morris (2000). "The problem of information overload in business organisations: a review of the literature." International Journal of Information Management 20(1): 17-28.

[10] Gaudioso, F., O. Turel and C. Galimberti (2017). "The mediating roles of strain facets and coping strategies in translating technostressors into adverse job outcomes." Computers in Human Behavior 69: 189-196.

[11] Gudur, R. R., A. Blackler, V. Popovic and D. Mahar (2013). Ageing, technology anxiety and intuitive use of complex interfaces. IFIP Conference on Human-Computer Interaction, Springer.

[12] Hair Jr, J. F., G. T. M. Hult, C. Ringle and M. Sarstedt (2016). A primer on partial least squares structural equation modeling (PLS-SEM), Sage Publications.

[13] Hung, W.-H., L.-M. Chang and C.-H. Lin (2011). Managing The Risk Of Overusing Mobile Phones In The Working Environment: A Study Of Ubiquitous Technostress. PACIS.

[14] Jena, R. (2015). "Technostress in ICT enabled collaborative learning environment: An empirical study among Indian academician." Computers in Human Behavior 51: 1116-1123.

[15] Judge, T. A., R. Ilies and B. A. Scott (2006). "Workfamily conflict and emotions: Effects at work and at home." Personnel psychology 59(4): 779-814.

[16] Lazarus, R. S. (1991). "Progress on a cognitivemotivational-relational theory of emotion." American psychologist 46(8): 819.

[17] Lazarus, R. S. (2006). Stress and emotion: A new synthesis, Springer Publishing Company.

[18]Lazarus, R. S. and S. Folkman (1984). Stress, appraisal, and coping, Springer publishing company.

[19] Maier, C., S. Laumer, C. Weinert and T. Weitzel (2015). "The effects of technostress and switching stress on discontinued use of social networking services: a study of Facebook use." Information Systems Journal 25(3): 275308.
[20] Pirkkalainen, H., M. Salo, M. Makkonen and M. Tarafdar (2017). Coping with technostress: When emotional responses fail. ICIS 2017: Proceedings the 38th international conference on information systems, Association for Information Systems (AIS).

[21] Ragu-Nathan, T., M. Tarafdar, B. S. Ragu-Nathan and Q. Tu (2008). "The consequences of technostress for end users in organizations: Conceptual development and empirical validation." Information systems research 19(4): 417-433.

[22] Ringle, C. M., S. Wende and J.-M. Becker (2015). SmartPLS 3. Boenningstedt: SmartPLS GmbH.

[23] Salo, M., H. Pirkkalainen, M. Makkonen and R. Hekkala (2018). Distress, Eustress, or No Stress?: Explaining Smartphone Users ${ }^{\mathrm{TM}}$ Different Technostress Responses. International Conference on Information Systems, Association for Information Systems (AIS).

[24] Sarabadani, J., Carter, M., \& Compeau, D. (2018). 10 Years of Research on Technostress Creators and Inhibitors: Synthesis and Critique. American Conference on Information Systems (AMCIS)

[25] Speier, C., J. S. Valacich and I. Vessey (1999). "The influence of task interruption on individual decision making: An information overload perspective." Decision Sciences 30(2): 337-360.

[26] Stich, J.-F., M. Tarafdar, P. Stacey and S. C. Cooper (2019). "Appraisal of Email Use as A Source of Workplace Stress: A Person-Environment Fit Approach." Journal of the Association for Information Systems 20(2): 2.

[27] Tarafdar, M., E. Pullins and T. Ragu-Nathan (2011). Examining Impacts of Technostress on the Professional Salesperson's Performance. AMCIS.

[28] Tarafdar, M., Q. Tu, B. S. Ragu-Nathan and T. RaguNathan (2007). "The impact of technostress on role stress and productivity." Journal of Management Information Systems 24(1): 301-328.

[29] Tarafdar, M., Q. Tu and T. Ragu-Nathan (2010). "Impact of technostress on end-user satisfaction and performance." Journal of Management Information Systems 27(3): 303-334.

[30] Tu, Q., M. Tarafdar, T. Ragu-Nathan and B. S. RaguNathan (2008). "Improving end-user satisfaction through technostress prevention: some empirical evidences." AMCIS 2008 Proceedings: 236.

[31] Tu, Q., K. Wang and Q. Shu (2005). "Computer-related technostress in China." Communications of the ACM 48(4): 77-81.

[32] Weinert, C., C. Maier, S. Laumer and T. Weitzel (2019). How do users respond to technostress? An empirical analysis 
of proactive and reactive coping. Proceedings of the 52nd Hawaii International Conference on System Sciences.

[33] Yaverbaum, G. J. (1988). "Critical factors in the user environment: An experimental study of users, organizations and tasks." MIS quarterly: 75-88.

[34] Henseler, J., Ringle, C. M., and Sarstedt, M. (2015). A New Criterion for Assessing Discriminant Validity in Variance-based Structural Equation Modeling., Journal of the Academy of Marketing Science, 43(1): 115-135.

[35] Gefen, D., Straub, D.W., and Boudreau, M.C. "Structural equation modeling and regression: Guidelines for research practice," Communications of AIS (4, Article 7:October 2000)

[36] Rouse, A.C., and Corbitt, B. "There's SEM and "SEM : A critique of the use of PLS regression in Information Systems research," 19th Australasian Conference on Information Systems, Christchurch, NZ, 2008, pp. 845-855.

[37] Nikkhah, H. R., \& Sabherwal, R. (2017). A PrivacySecurity Model of Mobile Cloud Computing Applications.

[38] Steelman, Z. R., Hammer, B. I., \& Limayem, M. (2014). Data collection in the digital age: Innovative alternatives to student samples. Journal of Consumer Psychology, 23(2), 212-219.

[39] Lowry, P. B., D’Arcy, J., Hammer, B., \& Moody, G. D. (2016). "Cargo Cult" science in traditional organization and information systems survey research: A case for using nontraditional methods of data collection, including Mechanical Turk and online panels. The Journal of Strategic Information Systems, 25(3), 232-240.

[40] Rouse, S. V. (2015). A reliability analysis of Mechanical Turk data. Computers in Human Behavior, 43, 304-307.

[41] Karpouzis, K., Caridakis, G., Kessous, L., Amir, N., Raouzaiou, A., Malatesta, L., \& Kollias, S. (2007). Modeling naturalistic affective states via facial, vocal, and bodily expressions recognition. In Artifical intelligence for human computing (pp. 91-112). Springer, Berlin, Heidelberg.

\section{Appendix}

Table 1. Demographics

\begin{tabular}{|l|c|c|}
\hline & $\mathrm{N}$ & $\%$ \\
\hline Gender & & \\
\hline Male & 72 & 35.00 \\
\hline Female & 132 & 64.10 \\
\hline other & 2 & 1.00 \\
\hline Age & & \\
\hline Under30 years & 40 & 19.4 \\
\hline 31-40 years & 62 & 30.1 \\
\hline
\end{tabular}

\begin{tabular}{|l|c|c|}
\hline 41-50 years & 54 & 26.2 \\
\hline Above 50 years & 50 & 24.3 \\
\hline IT experience at work & & \\
\hline Less than 5 years & 57 & 27.7 \\
\hline 5-10 years & 51 & 24.8 \\
\hline 11 to 15 years & 40 & 19.4 \\
\hline More than 15 years & 58 & 28.2 \\
\hline Education & 2 & 1.0 \\
\hline Less than high school degree & 20 & 9.7 \\
\hline High school graduate & 46 & 22.3 \\
\hline Some college but no degree & 23 & 11.2 \\
\hline Associate degree & 71 & 34.5 \\
\hline Bachelor's degree in college & 31 & 15.0 \\
\hline Master's degree & 8 & 3.9 \\
\hline Doctoral degree & 5 & 2.4 \\
\hline Professional degree & 37 & 19.7 \\
\hline Industry & 26 & 13.8 \\
\hline Management and business & 27 & 14.4 \\
\hline $\begin{array}{l}\text { computer, engineering and } \\
\text { science }\end{array}$ & 23 & 12.2 \\
\hline $\begin{array}{l}\text { education, legal, Community } \\
\text { and Media }\end{array}$ & 17 & 9.0 \\
\hline Health care & 14 & 7.4 \\
\hline Sales & 31 & 6.9 \\
\hline Service & 16.5 \\
\hline Office and administration & \\
\hline Others & & \\
\hline
\end{tabular}

Table 2. Measurement Items

\begin{tabular}{|c|c|c|}
\hline Constructs & Items & Loadings \\
\hline \multirow[t]{4}{*}{$\begin{array}{l}\text { Techno- } \\
\text { overload }\end{array}$} & $\begin{array}{l}\text { I am forced by this } \\
\text { technology to work much } \\
\text { faster. }\end{array}$ & 0.78 \\
\hline & $\begin{array}{l}\text { I am forced by this } \\
\text { technology to work with } \\
\text { very tight time schedules. }\end{array}$ & 0.75 \\
\hline & $\begin{array}{l}\text { I am forced to change my } \\
\text { work habits to adapt to } \\
\text { new technologies. }\end{array}$ & 0.79 \\
\hline & $\begin{array}{l}\text { I have a higher workload } \\
\text { because of increased } \\
\text { technology complexity. }\end{array}$ & 0.74 \\
\hline \multirow[t]{4}{*}{$\begin{array}{l}\text { Techno- } \\
\text { invasion }\end{array}$} & $\begin{array}{l}\text { I spend less time with my } \\
\text { family due to this } \\
\text { technology. }\end{array}$ & 0.72 \\
\hline & $\begin{array}{l}\text { I have to be in touch with } \\
\text { my work even during my } \\
\text { vacation due to this } \\
\text { technology. }\end{array}$ & 0.75 \\
\hline & $\begin{array}{l}\text { I have to sacrifice my } \\
\text { vacation and weekend } \\
\text { time to keep current on } \\
\text { new technologies. }\end{array}$ & 0.76 \\
\hline & $\begin{array}{l}\text { I feel my personal life is } \\
\text { being invaded by this } \\
\text { technology. }\end{array}$ & 0.72 \\
\hline
\end{tabular}




\begin{tabular}{|c|c|c|}
\hline \multirow[t]{5}{*}{$\begin{array}{l}\text { Techno- } \\
\text { complexity }\end{array}$} & $\begin{array}{l}\text { I do not know enough } \\
\text { about this technology to } \\
\text { handle my job } \\
\text { satisfactorily. }\end{array}$ & 0.75 \\
\hline & $\begin{array}{l}\text { I need a long time to } \\
\text { understand and use new } \\
\text { technologies. }\end{array}$ & 0.75 \\
\hline & $\begin{array}{l}\text { I do not find enough time } \\
\text { to study and upgrade my } \\
\text { technology skills. }\end{array}$ & 0.67 \\
\hline & $\begin{array}{l}\text { I find new recruits to this } \\
\text { organization know more } \\
\text { about computer } \\
\text { technology than I do. }\end{array}$ & $0.59 *$ \\
\hline & $\begin{array}{l}\text { I often find it too complex } \\
\text { for me to understand and } \\
\text { use new technologies. }\end{array}$ & 0.83 \\
\hline \multirow[t]{4}{*}{$\begin{array}{l}\text { Techno- } \\
\text { insecurity }\end{array}$} & $\begin{array}{l}\text { I feel constant threat to } \\
\text { my job security due to } \\
\text { new technologies. }\end{array}$ & 0.76 \\
\hline & $\begin{array}{l}\text { I have to constantly } \\
\text { update my skills to avoid } \\
\text { being replaced. }\end{array}$ & $0.62 *$ \\
\hline & $\begin{array}{l}\text { I am threatened by } \\
\text { coworkers with newer } \\
\text { technology skills. }\end{array}$ & 0.819 \\
\hline & $\begin{array}{l}\text { I feel there is less sharing } \\
\text { of knowledge among } \\
\text { coworkers for fear of } \\
\text { being replaced. }\end{array}$ & 0.83 \\
\hline \multirow[t]{4}{*}{$\begin{array}{l}\text { Techno- } \\
\text { uncertainty }\end{array}$} & $\begin{array}{l}\text { There are always new } \\
\text { developments in the } \\
\text { technologies we use in our } \\
\text { organization. }\end{array}$ & 0.81 \\
\hline & $\begin{array}{l}\text { There are constant } \\
\text { changes in computer } \\
\text { software in our } \\
\text { organization. }\end{array}$ & 0.80 \\
\hline & $\begin{array}{l}\text { There are constant } \\
\text { changes in computer } \\
\text { hardware in our } \\
\text { organization. }\end{array}$ & 0.77 \\
\hline & $\begin{array}{l}\text { There are frequent } \\
\text { upgrades in computer } \\
\text { networks in our } \\
\text { organization. }\end{array}$ & 0.84 \\
\hline \multirow[t]{3}{*}{$\begin{array}{l}\text { Challenge } \\
\text { Emotions }\end{array}$} & $\begin{array}{l}\text { When I use technology to } \\
\text { accomplish work tasks I } \\
\text { feel hopeful. }\end{array}$ & 0.84 \\
\hline & $\begin{array}{l}\text { When I use technology to } \\
\text { accomplish work tasks I } \\
\text { feel anticipation. }\end{array}$ & 0.57 \\
\hline & $\begin{array}{l}\text { When I use technology to } \\
\text { accomplish work tasks I } \\
\text { feel energized. }\end{array}$ & 0.89 \\
\hline $\begin{array}{l}\text { Achievement } \\
\text { Emotions }\end{array}$ & $\begin{array}{l}\text { When I use technology to } \\
\text { accomplish work tasks I } \\
\text { feel satisfied. }\end{array}$ & 0.83 \\
\hline
\end{tabular}

\begin{tabular}{|c|c|c|}
\hline & $\begin{array}{l}\text { When I use technology to } \\
\text { accomplish work tasks I } \\
\text { feel pleased. }\end{array}$ & 0.83 \\
\hline & $\begin{array}{l}\text { When I use technology to } \\
\text { accomplish work tasks I } \\
\text { feel relief. }\end{array}$ & 0.73 \\
\hline \multirow[t]{4}{*}{$\begin{array}{l}\text { Deterrence } \\
\text { Emotions }\end{array}$} & $\begin{array}{l}\text { When I use technology to } \\
\text { accomplish work tasks I } \\
\text { feel anxious. }\end{array}$ & 0.69 \\
\hline & $\begin{array}{l}\text { When I use technology to } \\
\text { accomplish work tasks I } \\
\text { feel afraid. }\end{array}$ & 0.81 \\
\hline & $\begin{array}{l}\text { When I use technology to } \\
\text { accomplish work tasks I } \\
\text { feel worried. }\end{array}$ & 0.79 \\
\hline & $\begin{array}{l}\text { When I use technology to } \\
\text { accomplish work tasks I } \\
\text { feel stressed. }\end{array}$ & 0.83 \\
\hline \multirow[t]{5}{*}{$\begin{array}{l}\text { Loss } \\
\text { Emotions }\end{array}$} & $\begin{array}{l}\text { When I use technology to } \\
\text { accomplish work tasks I } \\
\text { feel angry. }\end{array}$ & 0.83 \\
\hline & $\begin{array}{l}\text { When I use technology to } \\
\text { accomplish work tasks I } \\
\text { feel dissatisfied. }\end{array}$ & 0.82 \\
\hline & $\begin{array}{l}\text { When I use technology to } \\
\text { accomplish work tasks I } \\
\text { feel annoyed. }\end{array}$ & 0.84 \\
\hline & $\begin{array}{l}\text { When I use technology to } \\
\text { accomplish work tasks I } \\
\text { feel frustrated. }\end{array}$ & 0.81 \\
\hline & $\begin{array}{l}\text { When I use technology to } \\
\text { accomplish work tasks I } \\
\text { feel disgust. }\end{array}$ & 0.79 \\
\hline
\end{tabular}

* Items were removed due to low item loadings.

Table3. Reliabilities, convergent and discriminant validity

\begin{tabular}{|l|l|l|l|l|l|l|l|l|l|l|l|}
\hline & CR & AVE & 1 & 2 & 3 & 4 & 5 & 6 & 7 & 8 & 9 \\
& & & & & & & & & & & \\
\hline 1 T-OVR & 0.85 & 0.59 & .77 & & & & & & & & \\
\hline 2 T-INV & 0.83 & 0.54 & .60 & .74 & & & & & & & \\
\hline 3 T-CMP & 0.84 & 0.57 & .39 & .52 & .75 & & & & & & \\
\hline 4 T-INS & 0.83 & 0.55 & .54 & .53 & .52 & .74 & & & & & \\
\hline 5 T-UNC & 0.88 & 0.65 & .43 & .30 & .10 & .53 & .80 & & & & \\
\hline 6 ACH & 0.84 & 0.67 & -.04 & -.09 & -.30 & -.03 & .26 & .80 & & & \\
\hline 7 CHL & 0.82 & 0.60 & .16 & .07 & -.19 & .11 & .21 & .66 & .78 & & \\
\hline 8 DTR & 0.86 & 0.62 & .32 & .34 & .54 & .32 & .01 & -.33 & -.13 & .78 & \\
\hline 9 LOSS & 0.91 & 0.67 & .25 & .32 & .51 & .36 & .07 & -.37 & -.32 & .70 & .80 \\
\hline
\end{tabular}

$\mathrm{T}-\mathrm{OVR}=$ Techno-overload, $\mathrm{T}-\mathrm{INV}=$ techno-invasion, $\mathrm{T}-\mathrm{COM}=$ Techno-complexity, $\mathrm{T}-\mathrm{INS}=$ Technoinsecurity, $\mathrm{T}-\mathrm{UNC}=$ Techno-uncertainty, $\mathrm{ACH}=$ achievement emotions, $\mathrm{CHL}=$ Challenge emotions, DTR $=$ Deterrence emotions, LOSS $=$ Loss emotions 